\title{
The Effects of Psychological Games on Communication Skills for Persuasion
}

\author{
Koshi Makino Contact information: koshim@kjo.setsunan.ac.jp \\ Department of Business Administration, Setsunan University (Japan)
}

Communication skills are a part of social skills, which work more directly for interpersonal relationship. Makino (2010) has researched on communication skills of juniorschool students and communication skills training for them in Japan. Makino (2012) examined the association between communication skills and friendship, their mental health. According to Makino (2012), as the person who had high communication skills for the same-sex, the friend relations were good and the mental health state was good.

This study examined the effects of psychological games on communication skills for persuasion of young people. Theoretical framework of this study is social learning theory and this study is based on social skil training for young people. It is supposed that the participants learn persuasive communication skills by watching and imitating others through the games. Werewolf-Game is often used as a psychological game(Tanno \& Kodama 2015). Werewolf game has about 10 participants and they were divided into 2 groups, werewolf team and citizen team. Werewolf tells a lie and attacks the citizens, citizens try to find the wolf by conversation and expel it. As for this game, games advance by conversation of all the participants. Participants must have discussions and need to persuade others in this game. Therefore, communication skills for persuasion become very important to win.

\section{Methods}

Survey participants were 60 university students (who have experienced few werewolf-game before, 36 males and 24 females, Average age is 20.62.). Half participants were divided into an experimental group, and the others were into a control group. The experimental group members played werewolf-games 6 times during 2 weeks, and the control group members did not. Their communication skills for persuasion (4 factors) were measured(7-point scale): logical argument, humor and empathy, profit of the partner, and faithful manner. The questionnaire was carried out 3 times: 2 weeks before the games, 2 weeks after the games, and 4 weeks after the games.

\section{Results}

The comparison between experimenta group and control group before the games.

The analysis design of this study is ANOVA (2(between: experimental, control) $\times 3$ (within: before, 2 weeks after the games, 4 weeks after the games). The dependen variables are 4 communication skills for persuasion.

As a result of ANOVA of the mean of each factor score between experimental group and control group before the games, there was no significant difference between them. This result revealed that there was no difference in their communication skills for persuasion between experimental and control group before the games.

The comparison between experimental group and control group after the games.

As a result of ANOVA $(2 \times 3)$ of the mean of each factor score, there were significant differences in all factors. 2 weeks after the games, all skills in experimental group became higher than before, and those skills were higher than those of control group. In addition, those skills were maintained high 4 weeks later(Figure 1 and Figure 2), but they were not higher than those of before the games. These results showed that the participants of experimental group learned how to persuade people through the games compared with the participants of control group. And those high skills were maintained four weeks later, which means this effect is not temporary.

\section{Discussion}

This study examined the effects of psychological games on communication skills for persuasion. The psychological games in this experiment raised all communication skills for persuasion of the participants in the

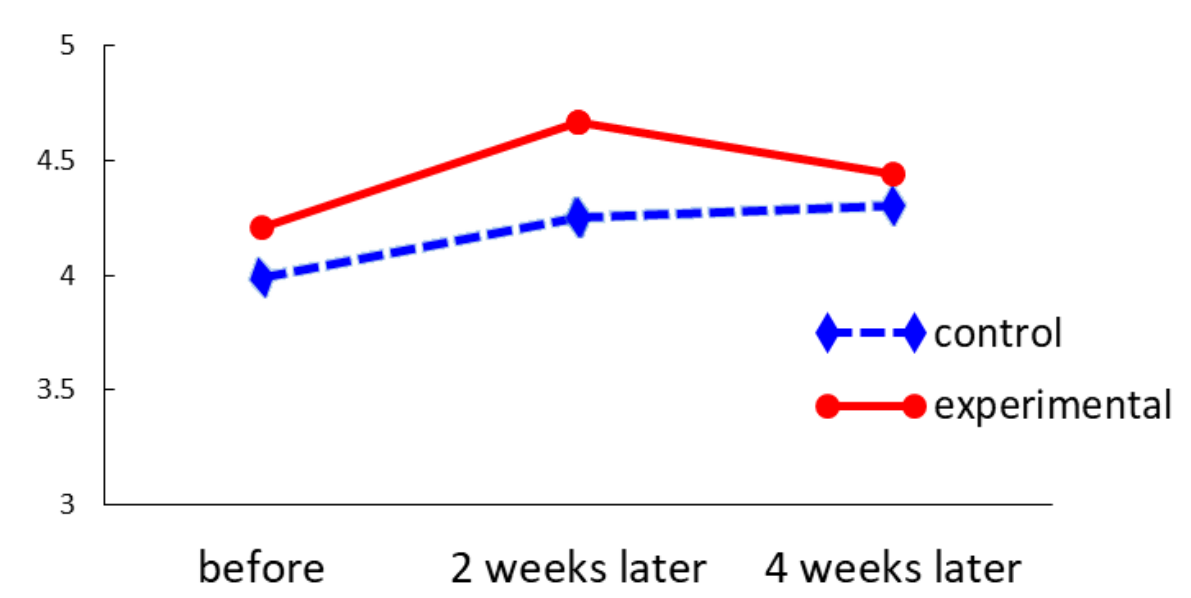

Figure 1. logical argument skill before and after the games experimental group and those skills were higher than those of control group, but the psychological mechanism was not elucidated. Moreover, those improved skills were maintained four weeks later, but those skills were not higher than those before the games. The participants acquired skills how to persuade people depending on the scene while enjoying the games. And those skills were maintained high for a while. These results indicate the possibility that communication skills for persuasion are promoted by the training using the psychological games.

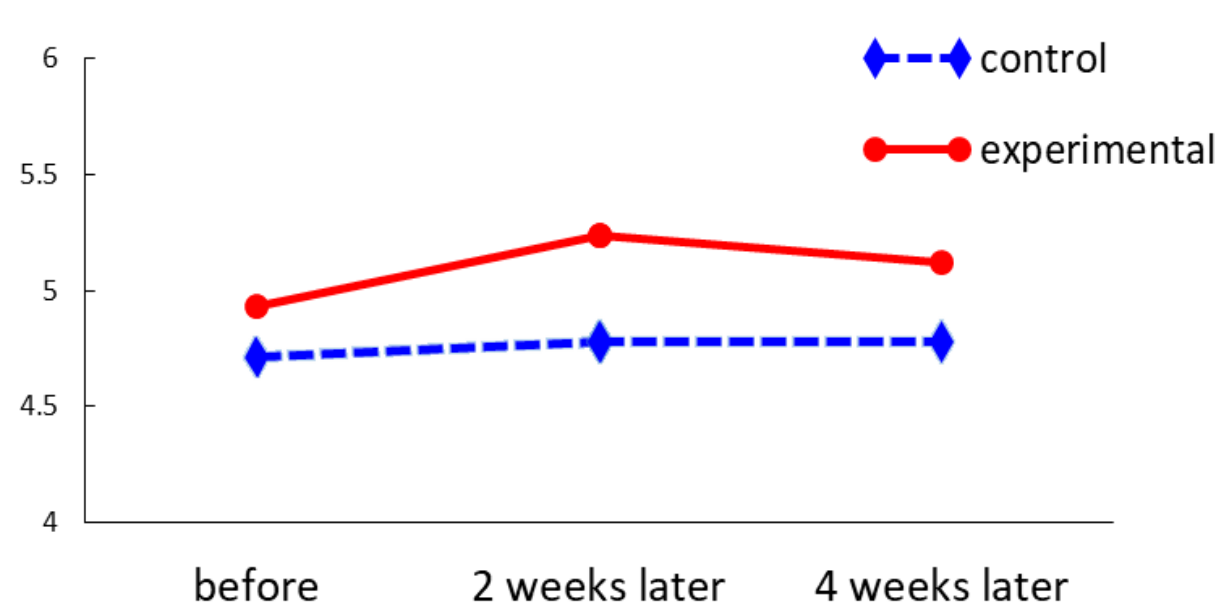

Figure 2. humor and empathy skill before and after the games

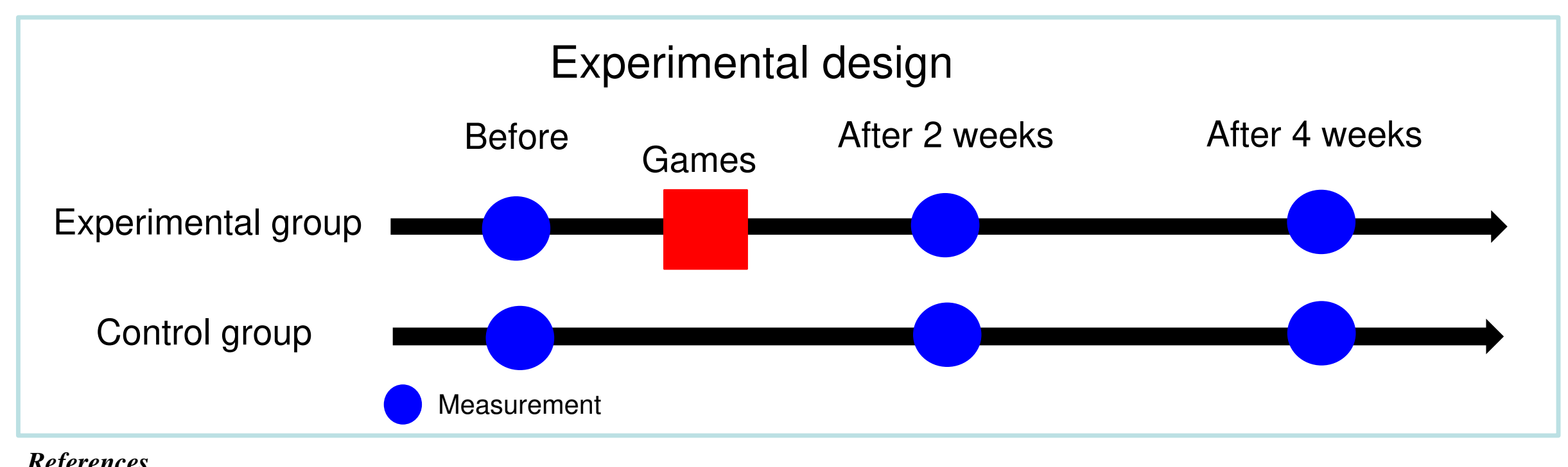

Makino, K. (2010). A Development of the Communication Skills Training for Junior High School Students (3). - The Effects of Communication Skills Training on Junior High School Students in Japan. - Journal of Business Administration and Information, 18, 1-9.

Makino, K. (2012). The Communication Skills and Friendship in Adolescence - The Sex and Grade Differences of Communication Skills for Friends of the Same and Opposite Sex - Journal of Business Administration and Information, 20, 17-32.

anno, H \& Kodama, T (2015). Deference in Beliefs about Lie Clues Related to Werewolf-Game Experience: Comparison amon Undergraduates, Werewolf-Game Fans, and Werewolf-Game Stage Actors The Japanese Journal of Personality, 24, 88-90. 